\title{
Employment Situation Analysis of Information Management Professionals of Qujing Normal College
}

\author{
Limei Cui \\ Qujing normal college, Yunnan Qujing city kirin sanjiang avenue 655011
}

\begin{abstract}
Keywords: Information processing; Professional competence; Knowledge transformation; Inter-disciplinary talent
\end{abstract}

\begin{abstract}
In the face of the current market situation, many college students face the pressure of employment, or even simply can't find a job, and a lot of college students had unemployment haven't find a job. For information management professional students, we should be more analysis to have a very professional analysis, find out the shortages and advantages, give students career as soon as possible, so that the students study have a clear goal, to lay a solid foundation for future employment.
\end{abstract}

\section{Introduction}

In the face of the development of information science and technology, the development of the discipline of fuse professional prospects should be optimistic, social demand for fuse graduates is also increasing. But information management specialized student employment situation in recent years did not meet expectations hope, why society for information management and information systems professional talents for the huge demand, and fuse professional facing huge employment pressure? The following is my this professional analysis:

\section{The Information Management of Professional Employment Advantage}

With the extensive popularization and application of information technology, the society and the enterprise informationization talented person's demand is bigger and bigger. And know both business, management, technology and knowledge of the inter-disciplinary talent is very lack in China. Information management major is a professional management and computer science, learning courses include management related courses, courses related to information retrieval, computer related courses and some of the financial aspects of knowledge. Is now a common phenomenon: management don't understand the technology, the computer professional don't understand management, and enterprise need of talents. For example, the construction of information system is a high complexity of system engineering. Not find a few technical personnel can solve the matter, has no experience in management, the accumulation of technology platform, professional means is difficult to achieve the effect of implementing, inter-disciplinary talent is defined as "know both management and understand the computer. And information management professional trained talent is a modern management science, economics, computer science and technology and its application of theoretical knowledge and basic skills, able to undertake the work of information management information system analysis, design, implementation and management, combined with their own innovation and the ability to practice and keep up with the requirements of The Times, with the sustainable development potential of specialized talents.

Work is related to the major is the implementation of the management information system or developed, many of them are doing enterprise ERP, both work requirements for enterprises particularly familiar with the business, management, financial knowledge is also needed, and should often communicate with business leaders and employees, and implementation need to be familiar with the corresponding software (such as ufida, kingdee, abroad have SAP, Oracle, etc.), language development and development need to know. Also can go to the department in the enterprise information work, maintain the information system, etc. If the fuse professional students after strict training, to achieve the requirement of the enterprise, the fuse professional students will become hot 
hot property. Management professional don't understand the technology, the computer professional don't understand management, enterprise more now is need comprehensive talents. Certainly, as long as the fuse professional students learn professional enough, complex became our strengths.

\section{The Information Management Professional obtain Employment Disadvantage}

For information management professional students, many are their first choice back admission, our professional knowledge is not much, what to learn, how to learn, to learn what can be done after all is lost. Information management major is a professional management and computer science, is of course generally includes management related courses, courses related to information retrieval and computer courses. Many students believe that after graduating from this major will appear as both management skill for students majoring in management, also is inferior to the computer professional computer skills, learn the very complex but not jing.

Difficult employment reasons, first of all, unit of choose and employ persons is not good to realize fuse professional students strong competitiveness and enterprise itself the urgent needs of talents for the informatization. In China's industrial revolution is not yet complete, encountered the information revolution, information technology has just started to get into the Internet age. But the ideas of conformism is the biggest obstacle of informationization, and informationization talented person can not get the attention they deserve the real culprit. Second, the way of teaching information management major of our college cultivate students is not up to the requirement of the enterprise. Because in most of the teachers' teaching from computer science and related professional, they have ability to computer information technology, is the lack of management knowledge as well as how to put the computer knowledge organically combined with the management, make it different from computer software professional and specialized in computer application. In the process of professional training will learn the basic knowledge of enterprise management, accounting, as well as the course of computer knowledge, but these courses in the university study is incomplete, and even learned the content, mostly because there is no system and ERP system with specific cases of study, can't lead to knowledge directly into their work ability, create value for the enterprise. Such a cultivated students' lack of professional quality, the enterprise can't recruit to the box, of course will have a headache can't find a job for graduates.

Although information management major is emphasizes the multidisciplinary integration, but in the usual learning is passive to accept multidisciplinary in the process of learning, some basic knowledge, at best, multi-disciplinary heap just tired, but also some teachers just scripted, let alone multidisciplinary fusion penetration fully, causes students to not be able to learn knowledge into concrete applications. Computer knowledge than deep computer professional, learn than school of management, fine management.

Anyhow, fuse learn every subject of depth is more important than the professional students is the lack of practice in the process of learning at ordinary times, how many knowledge know principle, but I don't know how to operation, how to complete a task specific, companies now need to complete the task well, create value for enterprise talent, not an only know say, don't know what to do.

\section{Information Management Professional Jobs}

The 21st century is the era of information science and technology leap development, with the development of global economic integration situation, the information for each person become more and more important, information management and information systems professional training of talents will also get the favour of talent market. Economic globalization and after China's accession to the WTO, IT enterprises usher in unprecedented development opportunities and pressures, the enterprises not only need the computer soft, network engineers, more in need of information construction development and management talents, for enterprises and institutions and departments of the development and maintenance of application system, the development and utilization of information resources. 
Modern society is the information society, a lot of information on how to manage numerous and complicated, and obtaining effective information, the research emphasis is information management. What is more important in the case of a highly developed modern information technology, the demand of information to the user, implementations from the complete information is transformed into information in time, general information into a high-quality goods information, focus on information carrier physical image into information content itself. And combined with computer, computer as a tool, makes the information management more effective and practical. At present, information management involving many industries, such as consulting, services, logistics information services of crossover and integration, the commercialization of the Internet information services, integration and internationalization, and the progress of the global information network, both need a great deal of information management personnel, also provides many jobs.

\section{The Information Management Professional Employment}

Since the informatization degree, this door open information management professional colleges and universities and the college education is more and more talents of information management, thus management talent competition is becoming more and more fierce.

At present a lot of famous university also in this course, and the number and scale is becoming more and more big, education level and teaching level is relatively high, relatively speaking students' professional foundation level and other quality also is higher, it's the gap and our professional level, led to the employment competitive power is relatively backward. Compared with specialized technical personnel at the same time, the interdisciplinary knowledge of system is not perfect, the understanding of knowledge is not enough profound, the competitiveness of the course is less than the others, and therefore in the process of choosing jobs is easy to be eliminated by the company. And every year more and more undergraduate graduation, putting pressure on employment competition.

Based on the analysis of above, information management professional prospect is good. Based play in mind, as long as we are able to learn professional knowledge to learn deep jing, at ordinary times to expand their own various aspects ability, especially the application of professional knowledge and practical ability to grasp skilled operation, believe that our school information management professional students will have good jobs.

\section{References}

[1] The fee into, E.M Song, Information management construction of the chain of specialized courses and practice [J]. Figure books intelligence knowledge, 2014, (2) : 4-10.

[2] The king that is strong, M.S Cheng, Based on the career planning of information management professional talent training scheme to build research [J]. 2013 (17).

[3] Q Zhao, Consideration of information management and information systems professional position [J]. Journal of management informationization in China, 2012, 15 (1): 80-81.

[4] The king, and manganese, take a left, Chen. Big data environment information management professional talent training mode analysis and construction [j]. Journal of the library, 2015 (12) : 90.

[5] Everett m. Rogers. Innovation diffusion [M]. X Xin, eds. Beijing: central compilation press, 2002:10 to 30 . 